\title{
Characterization of Magnesium-Polylactic Acid Films Casted on Different Substrates and Doped with Diverse Amounts of CTAB
}

\author{
Margarita Hierro-Oliva ${ }^{1,2,3}$, Verónica Luque-Agudo ${ }^{1,2,3}$, Amparo M. Gallardo-Moreno ${ }^{1,2,3}$ \\ and M. Luisa González-Martín 1,2,3,* \\ 1 Department of Applied Physics, Faculty of Science, University of Extremadura, 06006 Badajoz, Spain; \\ margahierro@unex.es (M.H.-O.); vluque@unex.es (V.L.-A.); amparogm@unex.es (A.M.G.-M.) \\ 2 Networking Research Center on Bioengineering, Biomaterials and Nanomedicine (CIBER-BBN), \\ 06006 Badajoz, Spain \\ 3 University Institute of Extremadura Sanity Research (INUBE), 06006 Badajoz, Spain \\ * Correspondence: mlglez@unex.es
}

\section{check for} updates

Citation: Hierro-Oliva, M.; Luque-Agudo, V.; Gallardo-Moreno, A.M.; González-Martín, M.L. Characterization of MagnesiumPolylactic Acid Films Casted on Different Substrates and Doped with Diverse Amounts of CTAB. Molecules 2021, 26, 4811. https://doi.org/ $10.3390 /$ molecules 26164811

Academic Editor:

Katarzyna Szymczyk

Received: 12 July 2021

Accepted: 5 August 2021

Published: 9 August 2021

Publisher's Note: MDPI stays neutral with regard to jurisdictional claims in published maps and institutional affiliations.

Copyright: (c) 2021 by the authors. Licensee MDPI, Basel, Switzerland. This article is an open access article distributed under the terms and conditions of the Creative Commons Attribution (CC BY) license (https:// creativecommons.org/licenses/by/ $4.0 /)$.

\begin{abstract}
Polylactic acid (PLA) is a good candidate for the manufacture of polymeric biodegradable biomaterials. The inclusion of metallic particles and surfactants solves its mechanical limitations and improves its wettability, respectively. In this work, cetyltrimethylammonium bromide (CTAB) and magnesium particles have been incorporated into PLA films to evaluate the changes produced in the polymeric matrix cast on glass and silicone substrates. For this purpose, the surface of the films has been characterized by means of contact angle measurements and ToF-SIMS. Depth profiles and SEM images of the cross sections of the films have also been obtained to study their morphology. The results show that the CTAB in the polymer matrix with and without magnesium improves the wettability of the films, making them more suitable for cell adhesion. The higher the hydrophilicity, the higher the surfactant concentration. The depth profiles show, for the first time, that, depending on the surfactant concentration and the presence of $\mathrm{Mg}$, there is a layer-like distribution near the surface where, in addition to the CTAB + PLA mixture, a surfactant exclusion zone can be seen. This new structure could be relevant in in vitro/in vivo situations when the degradation processes remove the film components in a sequential form.
\end{abstract}

Keywords: polylactic acid; surfactants; magnesium; surface characterization

\section{Introduction}

Polylactic acid (PLA) is undoubtedly one of the most valuable, biodegradable, bioabsorbable, and sustainable polymers. Its use mainly covers the manufacture of biomedical devices, but also extends to different food, cosmetic, and pharmaceutical packaging applications [1]. Its interesting properties of non-toxicity and biocompatibility have prompted research to improve some of its other characteristics that appear as shortcomings in order to broaden its field of application. In particular, its mechanical behavior is very limited [2]. Its low ductility is one of its main drawbacks as a packaging material. On the other hand, even under low levels of stress, PLA tends to deform, permanently causing the loosening of the biodegradable fixation, and its low mechanical strength makes it unfeasible for a PLA orthopedic implant to maintain adequate performance until the bone grows sufficiently to restore its functionality [2].

Different strategies have been pursued to adapt PLA to the requirements necessary for its intended use [3]. A common methodology to endow the material with new properties is the inclusion within the polymeric matrix of dispersed particles or fibers. Cellulose and eucalyptus microfibers are added to improve the mechanical properties and barrier properties of PLA for food packaging applications [4-6]. Hydroxyapatite or magnesium 
phosphate fibers are included in PLA for the electrospinning fabrication of biomedical devices $[7,8]$.

However, one of the most promising alternatives to improve the mechanical behaviour of PLA is the addition of magnesium particles to the polymer matrix $[9,10]$. Magnesium is a biocompatible and biodegradable metal. Its use, pure or in alloy, is intensively investigated for the fabrication of implants [11,12]. However, the low corrosion resistance and undesirable hydrogen production of this metal has led researchers to consider the inclusion of $\mathrm{Mg}$ microparticles in a PLA matrix as an alternative composite material. The biodegradability of magnesium appears as a very complementary property to the biodegradability of PLA. This synergy makes this composite very attractive as it meets the mechanical properties suitable for use in orthopedic devices and allows the implant to be fully reabsorbed by the body [13].

The first contact between an implant and the physiological environment is through the surfaces. Regarding biocompatibility, wettability is a determining characteristic of the material surface [14]. Arima and Iwata posited that surfaces whose water contact angle is around $40-60^{\circ}$ are suitable for HeLa cells adhesion [15], and in general, moderately hydrophilic surfaces have been shown to be the most suitable for cell adhesion, spreading, and growth [14]. From this perspective, PLA needs improvements as its surface is hydrophobic. The inclusion of surfactants within the polymer matrix is one methodology followed to decrease the hydrophobicity of PLA. Zhang and Severtson studied the distribution of sodium alkyl sulphate surfactants in a polymer film and found that due to the enrichment of the interface with surfactant, the polymer contact angle changed from $\sim 110^{\circ}$ to $\sim 15^{\circ}$, depending on the concentration and the surfactant [16]. Kiss et al. using Pluronic surfactants $[17,18]$ found differences in water contact angle between $40^{\circ}$ and $10^{\circ}$ for PLA films without and with surfactants. Similar results were found by many other researchers working with different surfactants, such as Fukuoka et al. [19] or Gifu et al. [20] among others [17,21]. However, Gromer et al. [22], studying the surfactant distribution in films made from polymeric colloids, have shown that there are a large number of factors affecting the surfactant content along the film thickness, such as the type of surfactant and its initial concentration, the inorganic particles present, the size, shape, and thickness of the film, the aging conditions, and even the substrate on which the film is poured.

On this basis, the objective of this research is to evaluate the surface and internal changes of PLA composite films with magnesium particles due to the inclusion of a surfactant in their preparation. The films will be prepared by solvent casting, without the presence of water, using two substrates with different hydrophobicity for casting that can induce changes in the surface properties of the material [19]. The surfactant will be cetyltrimethylammonium bromide (CTAB). This cationic surfactant is relatively safe and frequently used in disinfection and cleaning procedures because of its antimicrobial properties $[23,24]$, in addition to the fact that even a trace amount of surfactant provides an effective strategy to reduce biofilm formation [25].

Wettability and compositional distribution will be the parameters analyzed. Therefore, water and diiodomethane contact angles will be measured on the films to evaluate their hydrophobicity and surface free energy. Likewise, the ToF-SIMS technique will be used to acquire the mass spectra at the surface and as a function of the film depth, for each one of the samples under study, in order to ascertain the distribution of the surfactant within the matrix as a function of the surfactant concentration, presence of magnesium, and substrates used in the manufacture.

\section{Materials and Methods}

\subsection{Films Preparation}

Glass disks samples were immersed in chromic acid for $15 \mathrm{~min}$ and then rinsed with distilled water. Silicone wafers were rinsed with absolute ethanol and dried with a flow of $\mathrm{N}_{2}$. They were kept in the desiccator until use. 
Polylactic acid (PLA) particles (PLA2003D, with D-isomer content of $4.25 \%$, purchased from NatureWorks LLC, Blair, NE, USA) were dissolved in chloroform (Sigma-Aldrich, Merck, Darmstadt, Germany) ( $5 \% w / v)$ using a rotator stirrer (JP Selecta, Barcelona, Spain). For preparation of films containing magnesium, magnesium particles $(\leq 50 \mu \mathrm{m}$, Nitroparis, Castellón, Spain) were added $(3 \% w / w)$ to the solution and stirred until complete homogenization. To determine the concentration of magnesium to be included, previous adhesion and bacterial viability tests were carried out, choosing the $3 \%(w / w)$ concentration because it causes bacterial damage but without reaching $100 \%$ mortality. Once the polymer solutions were prepared, varying amounts of cetyltrimethylammonium bromide (CTAB, Sigma-Aldrich, Merck, Darmstadt, Germany) $(0.5,1,5$, and $10 \% w / w)$ were added and stirred until completely dissolved. These CTAB concentrations were chosen to sweep a wide range around the MIC.

The nomenclature system of the films is as follows: A-PLA-x/y, where A is S for films casted on silicone and $\mathrm{G}$ for films casted on glass; $x$ represents the magnesium concentration and can be 0 or $3 \%(w / w)$ and $y$ represents the CTAB concentration, and can be $0,0.5,1,5$, and $10 \%(w / w)$.

Briefly, $1 \mathrm{~mL}$ or $2 \mathrm{~mL}$ of each solution was cast on silicone wafers or glass disks (respectively). The volumes of solution to be deposited depend on the area of the substrate and the thickness of the film to be obtained. Thus, since the diameter of the samples is different, it is necessary to deposit $2 \mathrm{~mL}$ of PLA solution on the glass to obtain a thickness equivalent to that of the samples prepared on silicone. Samples were left to dry first at room temperature for $24 \mathrm{~h}$ and later in an oven at $70^{\circ} \mathrm{C}$ for $24 \mathrm{~h}$, to completely remove any remaining solvent [26]. After that, the films thus prepared were peeled off the silicone wafers and glass disks. Surface characterization was carried out on the side in contact with the substrate. Complementary measurements were also made on the side in contact with the air to check if both sides behaved similarly.

\subsection{Contact Angle Measurement}

Static deionized water (Milli-Q Integral 5 System, Merck, Darmstadt, Germany) and diiodomethane (Fluka, Thermo Fisher Scientific, Waltham, MA, USA) contact angle measurements were carried out with a Drop Shape Analyzer-DSA100E system (Krüss, Hamburg, Germany) by the sessile drop method. Drops were photographed at $15 \mathrm{~s}$ after deposition. The results of contact angles, namely averaged values of at least three independent films, were analyzed for each of the conditions studied and two drops of each liquid were deposited per film.

\subsection{Surface Structure Characterization}

Cross sections of the films were obtained with the aid of a surgical knife. Microstructural analyses of cross-sectioned samples were performed by scanning electron microscopy (SEM, Hitachi S-4800, Chiyoda, Tokyo, Japan). The operation was performed under high vacuum conditions, with gold coating of the surface of the section exposed. Images were taken in the secondary electron (SE) mode.

\subsection{Surface and Depth Profile Chemical Composition}

Time of flight secondary ion mass spectrometry (ToF-SIMS) analyses of samples were performed with a Tof-SIMS 5 (ION TOF, Münster, Germany) using a $\mathrm{Bi}_{3}{ }^{2+}$ as primary gun, which operated at $25 \mathrm{keV}$. The total ion dose used to acquire each spectrum was above $10^{12}$ ions $/ \mathrm{cm}^{2}$. Negative spectra were recorded, and a pulsed low energy electron flood gun was used for charge neutralization. For samples containing $\mathrm{Mg}$, positive spectra were also collected to see the evolution of the $\mathrm{Mg}^{2+}$ ion. The depth profiles were performed using a $\mathrm{Bi}_{3}{ }^{2+}$ beam for analysis and an $\mathrm{Ar}^{+}$cluster (size of the cluster 1550 atoms) as a sputtering source, which operated at $10 \mathrm{keV}$ energy. The total ion dose was above $10^{12}$ ions $/ \mathrm{cm}^{2}$ per spectrum also for the depth profiles. The spot size for the surface spectra 
was $250 \mu \mathrm{m} \times 250 \mu \mathrm{m}$ and for the depth profiles was $300 \mu \mathrm{m} \times 300 \mu \mathrm{m}$ of sputter area and $50 \mu \mathrm{m} \times 50 \mu \mathrm{m}$ of analysis area.

The depth of the crater made in the depth profile was measured by optical profilometry, using a 3D Optical Surface Metrology System Leica DCM8 (Leica, Wetzlar, Germany).

\section{Results and Discussion}

\subsection{Surface Analysis of the Films}

The presence of varying amounts of CTAB and magnesium particles and the use of two types of substrates (one hydrophobic and another hydrophilic) to cast the PLA films can induce changes in the surface properties of the material [19]. Moreover, after manufacturing the films, we observed, especially for the films with higher CTAB content, a greater accumulation of $\mathrm{CTAB}$ at the edges than in the center, and a better homogeneity in this area. For this reason, we decided to carry out all the measurements in the center of the films and not at the edges because, in this latter region, the evaporation is faster and the particles may pack up sooner [27], keeping traces of the solvent occluded.

The surface composition of the films was evaluated by analyzing the ToF-SIMS surface mass spectra. Figure 1 shows the relative intensities of the characteristic ions of the surfactant and the polymer as a function of sample type. The bromide ion $\left(\mathrm{Br}^{-}\right)$was chosen as a representative fragment to determine the $\mathrm{CTAB}$ content, while the $\mathrm{C}_{4} \mathrm{H}_{7} \mathrm{O}_{2}{ }^{-}$fragment was selected for PLA. Both the surfactant and the polymer have hydrocarbon moieties in their structures, but the one considered for the analysis is unequivocally assigned to PLA and not to $C T A B$ as it contains oxygen and no nitrogen.

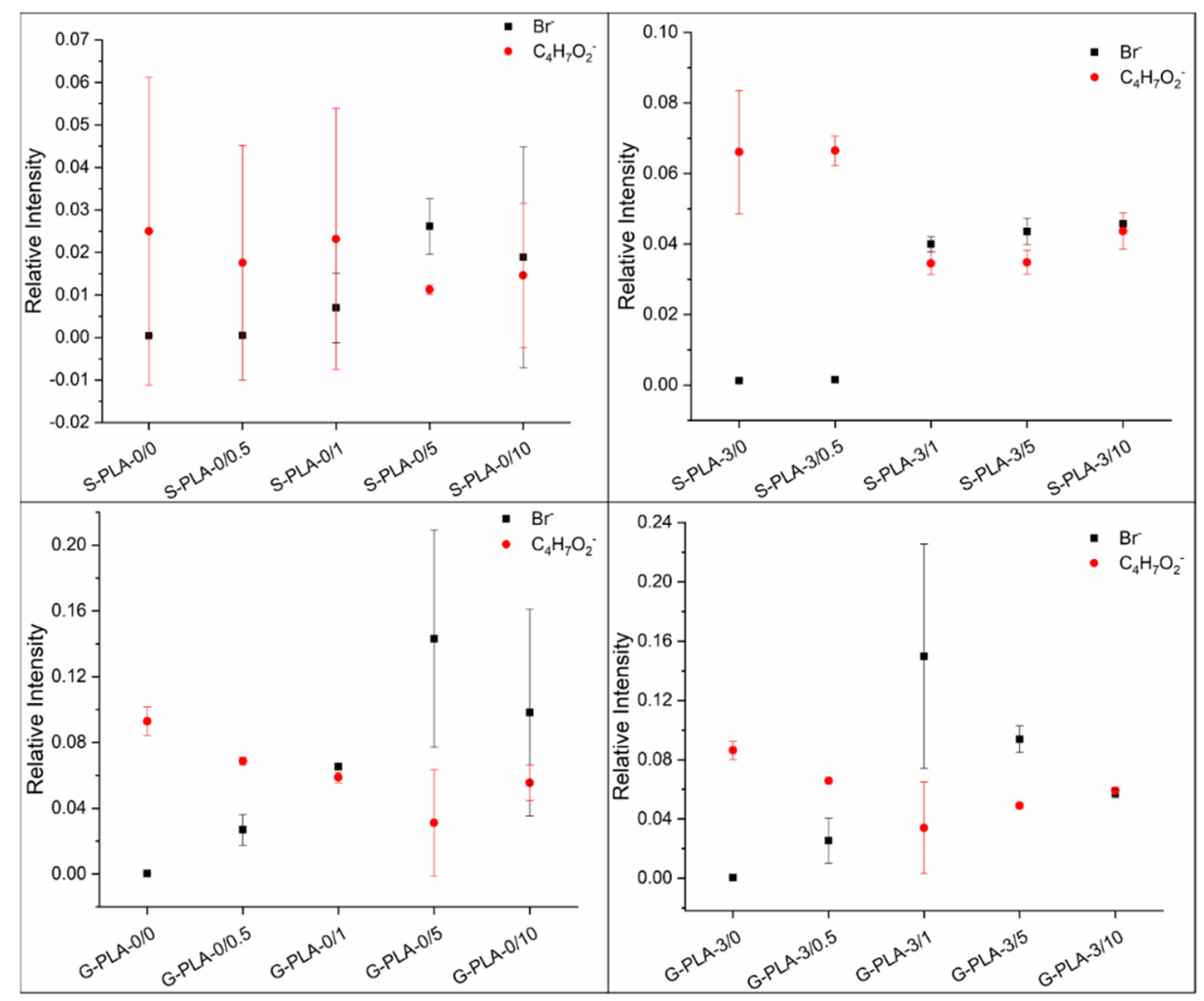

Figure 1. Relative intensities of $\mathrm{Br}^{-}$and $\mathrm{C}_{4} \mathrm{H}_{7} \mathrm{O}_{2}{ }^{-}$ions as a function of sample type for PLA films containing $\mathrm{CTAB}$ and $\mathrm{Mg}$ casted on silicone and glass.

In general, the bromide ion is poorly detected on the surface of films prepared with low $\mathrm{CTAB}$ concentrations and when the surfactant concentration increases this trend is reversed and the presence of surfactant becomes noticeable on the surface. This observation also seems to be dependent on the presence of $\mathrm{Mg}$ inside the film. In the films without $\mathrm{Mg}$ (S-PLA- $0 / x$ and G-PLA-0/x), CTAB starts to be relevant on the surface at concentrations 
of to $5 \%(w / w)$ and above, while in Mg-containing films CTAB starts to be present on the surface from a concentration of $1 \%(w / w)$.

The side of the film exposed to air during the drying process has also been analyzed and, although the trend is similar (Supplementary Materials), no changes as a function of CTAB content were observed in the values of the contact angles measured on that side (unpublished data). The study of the wettability of the samples as a function of the contact angle values was carried out on the side of the film in contact with the substrate (Table 1).

Table 1. Contact angles of water $\left(\theta_{\mathrm{W}}\right)$ and diiodomethane $\left(\theta_{\mathrm{D}}\right)$ on silicone, glass and the silicone and glass-casted films made of PLA, Mg particles and CTAB at the film-substrate interface.

\begin{tabular}{cccccc}
\hline Sample & $\boldsymbol{\theta}_{\mathbf{W}}\left({ }^{\circ}\right)$ & $\theta_{\mathbf{D}}\left(^{\circ}\right)$ & Sample & $\theta_{\mathbf{W}}\left({ }^{\circ}\right)$ & $\theta_{\mathbf{D}}\left(^{\circ}\right)$ \\
\hline Silicone & $113 \pm 2$ & $82 \pm 6$ & Glass & $43 \pm 4$ & $48 \pm 1$ \\
S-PLA-0/0 & $107 \pm 1$ & $64 \pm 2$ & G-PLA-0/0 & $75 \pm 4$ & $42 \pm 2$ \\
S-PLA-0/0.5 & $106 \pm 3$ & $59 \pm 1$ & G-PLA-0/0.5 & $78 \pm 5$ & $45 \pm 3$ \\
S-PLA-0/1 & $99 \pm 4$ & $55 \pm 1$ & G-PLA-0/1 & $89 \pm 7$ & $50 \pm 5$ \\
S-PLA-0/5 & $78 \pm 10$ & $70 \pm 3$ & G-PLA-0/5 & $68 \pm 7$ & $50 \pm 4$ \\
S-PLA-0/10 & $83 \pm 8$ & $74 \pm 2$ & G-PLA-0/10 & $65 \pm 11$ & $50 \pm 5$ \\
S-PLA-3/0 & $99 \pm 4$ & $57 \pm 12$ & G-PLA-3/0 & $67 \pm 3$ & $46 \pm 4$ \\
S-PLA-3/0.5 & $99 \pm 3$ & $66 \pm 1$ & G-PLA-3/0.5 & $69 \pm 3$ & $43 \pm 2$ \\
S-PLA-3/1 & $88 \pm 5$ & $64 \pm 1$ & G-PLA-3/1 & $67 \pm 5$ & $51 \pm 5$ \\
S-PLA-3/5 & $66 \pm 1$ & $60 \pm 1$ & G-PLA-3/5 & $54 \pm 3$ & $58 \pm 7$ \\
S-PLA-3/10 & $61 \pm 2$ & $65 \pm 1$ & G-PLA-3/10 & $34 \pm 2$ & $51 \pm 1$ \\
\hline
\end{tabular}

The data shown in Table 1 indicate that there are significant differences between the water $\left(\theta_{\mathrm{W}}\right)$ contact angles depending on the substrate on which the samples are cast. The contact angles for water are always higher for samples deposited on silicone than on glass. This may be due to the difference in crystallinity between the two types of films. Li et al. [28] related an increase in the hydrophobicity of PLA to an increase in its crystallinity, because the methyl groups of the polymer chain were more exposed towards the surface. This orientation can occur naturally/spontaneously or can be mechanically induced, as demonstrated by these authors. In our case, it seems that, in S-PLA-0/0 films, these hydrophobic methyl groups tend to be oriented towards the silicone, also hydrophobic, while in G-PLA-0/0 films, due to the hydrophilic character of the substrate, these groups would be oriented towards the bulk. The high crystallinity of the films casted on silicone was already shown in a previous work of our group [26], in which the peaks corresponding to the $\alpha$ crystalline phase appeared to be very well defined. In this phase, the methyl groups were oriented outwards from the polymeric chain, which would corroborate the hydrophobicity of these samples and support the hypothesis stated above.

The differences between the contact angles of the samples casted on both substrates are even more significant when $\mathrm{Mg}$ is present in the film: water contact angle values are on average $30 \%$ lower for glass samples than for silicone samples. In our previous work [26], we also observed small differences in crystallinity when the films were doped with $\mathrm{Mg}$ particles $(10 \% w / w$ in that case). Although PLA crystallized in the $\alpha$ phase, we did find small displacements of the peaks in the diffractogram, due to a distortion in the polymer chain caused by the presence of the Mg particles. This distortion affects the packing and the spacing between chains, likely being responsible for the differences found in the contact angles.

Regarding CTAB-containing films, it has already been described that a higher presence of CTAB in polymeric samples increases the surface hydrophilicity [17]. This increase in wettability with the surfactant accumulation on the film surface was already observed by Gyulai et al. [21] using XPS analysis and working with different surfactant concentrations. Their study concluded that as the surface became richer in surfactant, it became more hydrophilic. In our case, the water contact angles have a common trend for both types of substrates and their values decrease when there is a high concentration of CTAB on the surface of the film (Figure 1 and Table 1). For both substrates, on films containing 
$0.5 \%(w / w)$ of $\mathrm{CTAB}$, the average water contact angle does not change, so small amounts of CTAB are not enough to modify the hydrophobic behavior of the polymer. This is in agreement with data inferred from ToF-SIMS surface mass spectra (Figure 1), where no significant amount of $\mathrm{CTAB}$ on the surface is detected at low surfactant concentration. In the case of higher $\mathrm{CTAB}$ concentrations, two factors could contribute to the significant changes in hydrophobicity. Firstly, it seems that the CTAB presence may decrease the crystallinity of PLA [10], and secondly, the polar head of CTAB (containing the $\mathrm{Br}^{-}$ion and the quaternary ammonium fragment) has hydrophilic character, so that, as the surfactant is already on the outermost face of the film (Figure 1), the hydrophobicity of the samples decreases. When $\mathrm{Mg}$ is present in the film, CTAB also hydrophilizes the surfaces, similarly to what happens in Mg-free films, but the differences are higher, probably because CTAB affects how the polymer chains are packed together with the Mg particles.

It is also noteworthy that the film surface seems to become saturated with CTAB from $5 \%(w / w)$ since samples containing $5 \%$ and $10 \%$ behave similarly within standard deviations. In those cases, the saturation in the film surfaces may provoke the displacement of the excess of surfactant both towards the edges and outwards. The transport of matter by horizontal diffusion has already been described by other authors $[29,30]$.

Regarding the vertical distribution of the surfactant in the film, its molecular structure must be taken into account. Gromer et al. [22] stated that hydrophobic surfactants are distributed homogeneously throughout the film, while hydrophilic ones tend to accumulate at the air and substrate sides, leaving the bulk impoverished. Moreover, Zhang and Severtson [16] explained the differences in accumulation between the film-substrate and the film-air interfaces, only in the case of surfactants dissolved in water. In that case, evaporation was faster at the film-air interface (because there was a direct contact with the atmosphere) than at the film-substrate interface. This was the reason for the higher surfactant accumulation at the film-air interface. In our case, CTAB is dissolved in chloroform where, although it is soluble, it is not as soluble as in water. This could explain the predominance of the interaction between the surfactant and the substrate over the evaporation rate of the chloroform at the film-air interface, leading to a higher accumulation of CTAB on the side of the film in contact with the substrate compared to the side exposed to the air. In addition, the compatibility of the system under study must be considered. In this range of high $\mathrm{CTAB}$ concentrations, according to our results (Figure 1) and in agreement with Mallégol et al. [31], it seems that during drying an excess of surfactant accumulates at the film-substrate interface [32,33].

Additionally, the contact angles of diiodomethane on these samples were measured (Table 1) in order to calculate the surface tension and its components, as summarized in Table 2. As mentioned above, the diiodomethane $\left(\theta_{\mathrm{D}}\right)$ contact angles depend on the substrate on which the samples are casted, being higher for samples deposited on silicone than on glass. Moreover, in Mg-containing films, diiodomethane contact angles are on average $20 \%$ lower for glass samples than for silicone samples.

Table 2. The dispersive $(\gamma \mathrm{d})$ and polar $(\gamma \mathrm{p})$ components and the surface tension of the solid $(\gamma S)$, calculated using the Fowkes model.

\begin{tabular}{cccccccc}
\hline Sample & $\gamma^{\mathbf{d}}\left(\mathbf{m J} / \mathbf{m}^{\mathbf{2}}\right)$ & $\gamma^{\mathbf{p}}\left(\mathbf{m J} / \mathbf{m}^{\mathbf{2}}\right)$ & $\gamma_{\mathbf{s}}\left(\mathbf{m J} / \mathbf{m}^{\mathbf{2}}\right)$ & Sample & $\gamma^{\mathbf{d}}\left(\mathbf{m J} / \mathbf{m}^{\mathbf{2}}\right)$ & $\gamma^{\mathbf{p}}\left(\mathbf{m J} / \mathbf{m}^{\mathbf{2}}\right)$ & $\gamma_{\mathbf{s}}\left(\mathbf{m J} / \mathbf{m}^{\mathbf{2}}\right)$ \\
\hline S-PLA-0/0 & $26 \pm 1$ & $0 \pm 0$ & $26 \pm 1$ & G-PLA-0/0 & $38 \pm 1$ & $6 \pm 2$ \\
S-PLA-0/0.5 & $29 \pm 1$ & $0 \pm 0$ & $29 \pm 1$ & G-PLA-0/0.5 & $37 \pm 2$ & $5 \pm 2$ & $44 \pm 3$ \\
S-PLA-0/1 & $31 \pm 1$ & $0 \pm 1$ & $32 \pm 1$ & G-PLA-0/1 & $34 \pm 3$ & $2 \pm 2$ & $36 \pm 5$ \\
S-PLA-0/5 & $23 \pm 2$ & $9 \pm 6$ & $32 \pm 7$ & G-PLA-0/5 & $34 \pm 2$ & $10 \pm 4$ & $45 \pm 7$ \\
S-PLA-0/10 & $21 \pm 1$ & $8 \pm 5$ & $28 \pm 6$ & G-PLA-0/10 & $34 \pm 3$ & $12 \pm 7$ & $46 \pm 10$ \\
S-PLA-3/0 & $30 \pm 7$ & $0 \pm 1$ & $31 \pm 8$ & G-PLA-3/0 & $36 \pm 2$ & $10 \pm 2$ & $46 \pm 5$ \\
S-PLA-3/0.5 & $25 \pm 1$ & $1 \pm 1$ & $26 \pm 1$ & G-PLA-3/0.5 & $38 \pm 1$ & $8 \pm 2$ & $46 \pm 3$ \\
S-PLA-3/1 & $26 \pm 1$ & $4 \pm 2$ & $30 \pm 2$ & G-PLA-3/1 & $33 \pm 3$ & $11 \pm 4$ \\
S-PLA-3/5 & $29 \pm 1$ & $14 \pm 1$ & $42 \pm 1$ & G-PLA-3/5 & $30 \pm 4$ & $21 \pm 4$ \\
S-PLA-3/10 & $26 \pm 0$ & $18 \pm 2$ & $44 \pm 2$ & G-PLA-3/10 & $34 \pm 1$ & $31 \pm 2$ & $50 \pm 8$ \\
\hline
\end{tabular}


The results obtained are in agreement with the hydrophobicity and chemical composition of the surface of the films: changes in both $\theta_{\mathrm{W}}$ and $\theta_{\mathrm{D}}$ also imply changes in the surface tension of the solid $\left(\gamma_{S}\right)$ and especially in the polar component $\left(\gamma^{\mathrm{p}}\right)$.

There is also a clear difference between S-PLA-0/0-0.5 and G-PLA-0/0-0.5 films (Table 2). Samples deposited on glass with small amounts of CTAB have a low but nonzero $\gamma^{\mathrm{p}}$ value, which infers a certain polarity to the surface, while those prepared on silicon are non-polar $\left(\gamma^{\mathrm{p}}=0 \mathrm{~mJ} / \mathrm{m}^{2}\right)$. For both substrates, there is a clear increase in the $\gamma^{\mathrm{p}}$ component as the amount of CTAB in the samples increases (Figure 2). For films non-containing $\mathrm{Mg}$, the inclusion of CTAB at concentrations above $5 \%(w / w)$ induces a significant increase in the polar component. The same behavior is also observed for the Mg-containing films, but at CTAB concentrations of $1 \%(w / w)$. Moreover, the increase of the polar component is much higher. In the dispersive component, it is noteworthy that, in films deposited on silicone and not containing magnesium, no significant change is observed up to CTAB concentrations higher than $1 \%(w / w)$. This trend is also valid for samples deposited on glass, with the difference that the $\gamma^{\mathrm{d}}$ component begins to decrease for concentrations higher than $0.5 \%(w / w)$. For magnesium-containing samples, deposited on both silicon and glass, the dispersive component shows practically no change as a function of the amount of $\mathrm{CTAB}$, taking into account the uncertainties associated with each value. For the surface tension, taking into account the uncertainties, no significant changes are observed as a function of the CTAB concentration, except in the case of films containing magnesium and with a very high surfactant content (5 and $10 \% w / w)$.

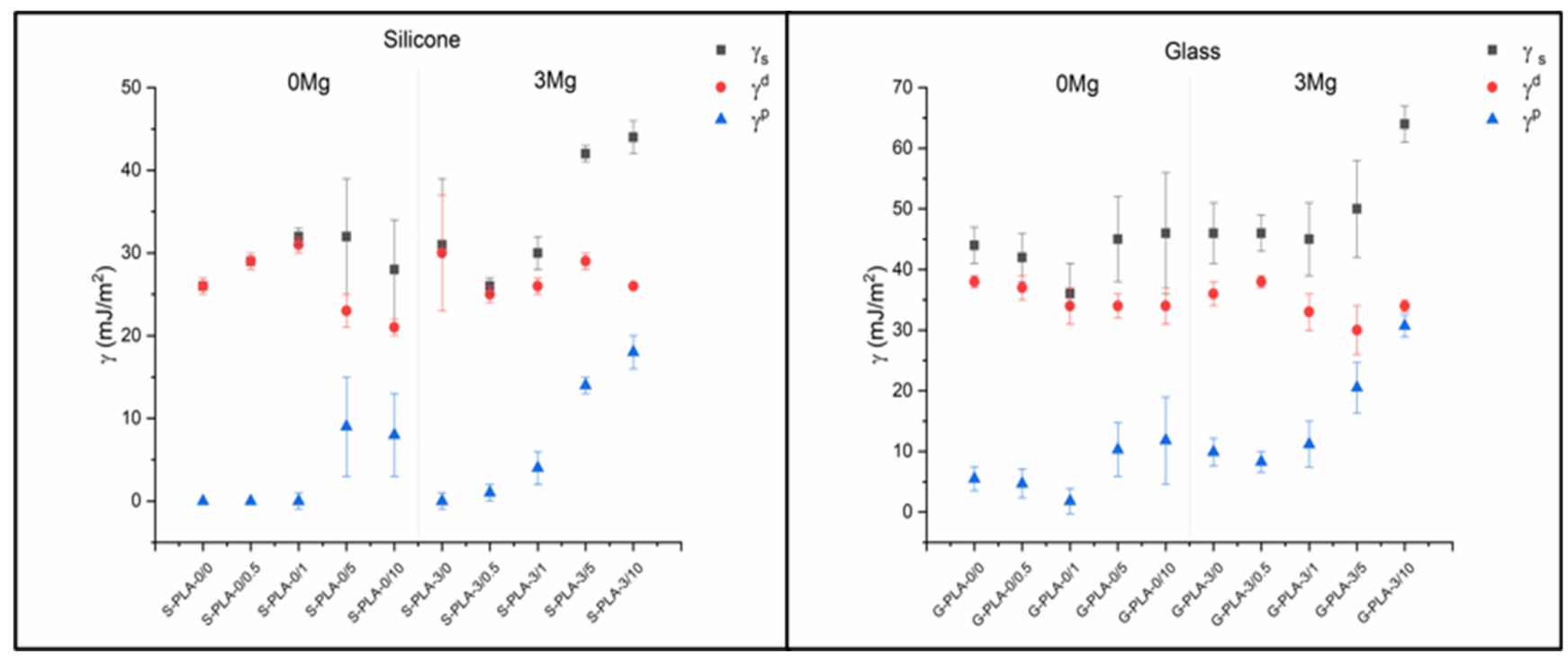

Figure 2. Surface tension $\left(\gamma_{\mathrm{S}}\right)$ and dispersive $\left(\gamma^{\mathrm{d}}\right)$ and polar $\left(\gamma^{\mathrm{p}}\right)$ components calculated using the Fowkes model.

\subsection{Internal Analysis of Films}

In order to check the internal distribution of components inside the casted films, the samples were analyzed by ToF-SIMS depth profiles and SEM cross-section images.

Figure 3 shows the depth profiles of the films casted on silicone with and without magnesium and without CTAB, with 1 and $10 \%(w / w)$ of CTAB. Depth profiles of the films casted on glass are analogous to S-PLA films (see Supplementary Materials).

In films without $\mathrm{Mg}$ (S-PLA- $0 / \mathrm{x}$ ), the presence of CTAB on the surface is only notorious at $10 \% w / w$ concentration (Figure $3 c$ ). Interestingly, at this concentration, just below this outer surface layer, CTAB is not found (between 20 and $75 \mathrm{~s}$ of sputtering, approximately), and then surfactant is again detected. From this information it can be derived that at $10 \% w / w$, there is a first layer of polymer, with a significant presence of CTAB, immediately followed by a layer of polymer and, after $75 \mathrm{~s}$ of sputtering, a third layer in which both PLA and surfactant are continuously blended. 


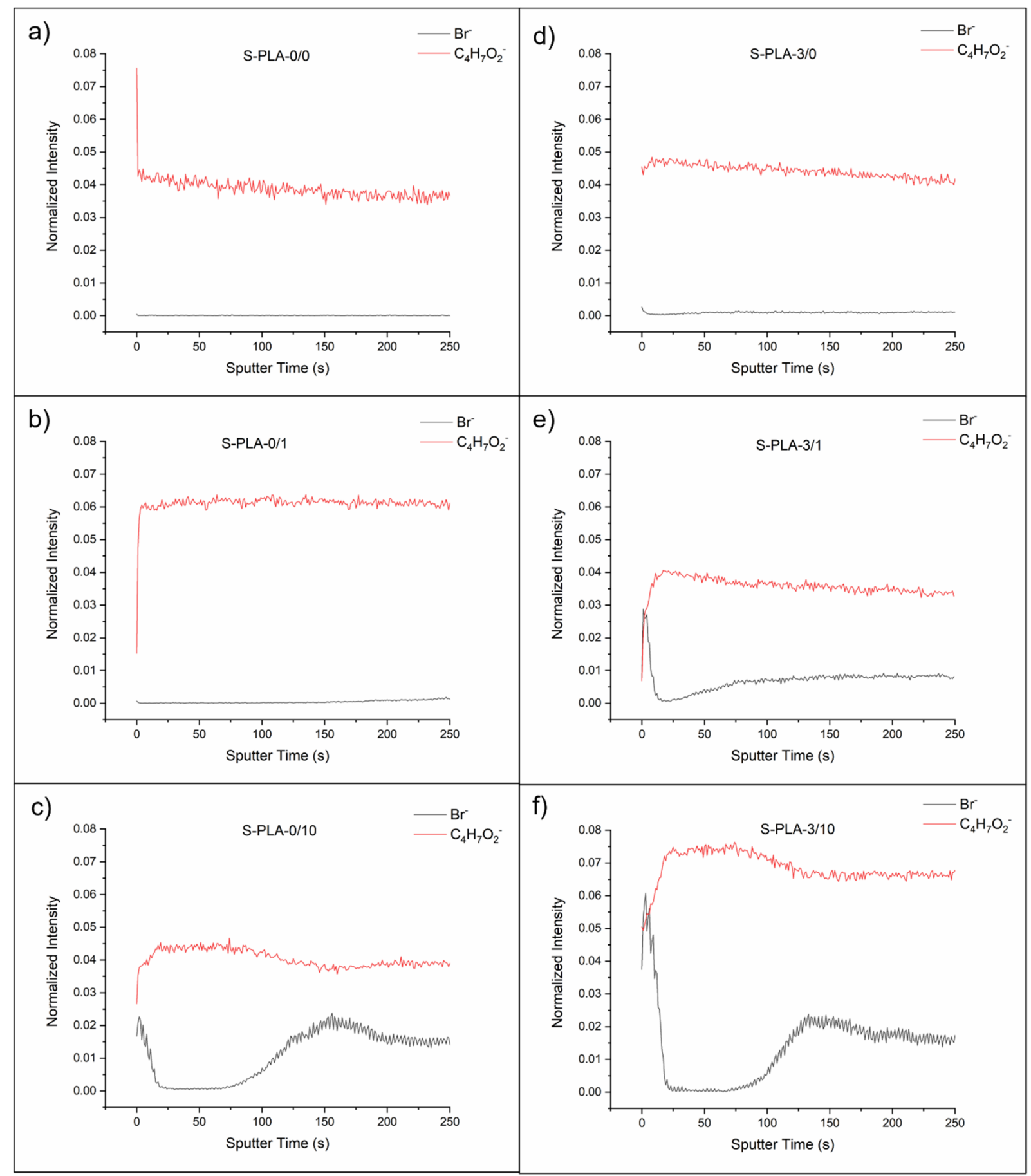

Figure 3. Depth profiles of S-PLA-0/0 (a), S-PLA-0/1 (b), S-PLA-0/10 (c), S-PLA-3/0 (d), S-PLA-3/1 (e) and S-PLA-3/10 (f) films.

In the case of films with Mg (S-PLA-3/x), this layered structure is already observed for concentrations of $1 \% w / w$, the first layer is somewhat diffuse and both components are blended (Figure 3e). The second layer is mainly composed of polymer and, at a depth located at about $30 \mathrm{~s}$ of sputtering, the third layer of PLA and CTAB mixed is found again. At higher concentrations, the layered structure is maintained (Figure 3f).

In order to confirm the presence of magnesium inside the film, the depth profiles were recorded in positive mode to track the $\mathrm{Mg}^{2+}$ cation (unpublished data), because in negative mode $\mathrm{MgO}^{-}$anion induces low signals. Moreover, as the applied ionization energy cannot be too high to extract the organic ions from the polymer-surfactant matrix, the amount of 
$\mathrm{Mg}^{2+}$ cations extracted in positive mode is enough to confirm their presence but is still low compared to the rest of the ions detected.

The depth profiles of the films were also recorded starting from the side exposed to air (see Supplementary Materials). In this case, as previously described in the surface analysis of films, it was observed that the accumulation of CTAB on the surface (higher the higher the surfactant concentration) was smaller than the accumulation on the film-substrate interface, which was related to the similar contact angles measured on that side. The layer structure observed on the surface in contact with the substrate is not so clearly defined in this case, with the outermost layer already being a mixture of CTAB and PLA.

Even though the layer-like structure inside the films has not been described before, data are partially supported by the research of Zhang and Severtson [16]. These authors showed that anionic surfactants tended to accumulate on the film surfaces, while non-ionic surfactants were homogeneously distributed throughout the film. Although the surfactant used in this work is cationic, electrical interactions must also be responsible for its increased accumulation on the surface, similar to that observed for anionic surfactants. This idea is also reinforced by the fact that the presence of $\mathrm{Mg}$ causes the accumulation of $\mathrm{CTAB}$ on the surface to be observed at lower surfactant concentrations, since the $\mathrm{Mg}^{2+}$ ions, dispersed in the polymeric matrix, must favor electrical repulsions with the CTAB molecules.

The morphology of the cross sections of the films was revealed by SEM images, as shown in Figure 4. In general, images show in some cases certain laminar structure of the polymeric matrix, which can be related to the sequential drying of the film (giving different arrangement of the polymer chains) or even to the mechanical forces exerted on the films during the peeling off from the silicone disks. This laminar structure is hard to relate to the different PLA-CTAB layers described previously in the depth profiles because the thickness of the ToF-SIMS craters, measured by optical profilometry, were small compared to the thickness of the films or of the laminar structure. A depth of approximately $6 \mu \mathrm{m}$ was reached when the sputtering time was $250 \mathrm{~s}$, which corresponds to the X-axis in Figure 3 (very long sputtering times, $1600 \mathrm{~s}$, reached to $55 \mu \mathrm{m}$ ).

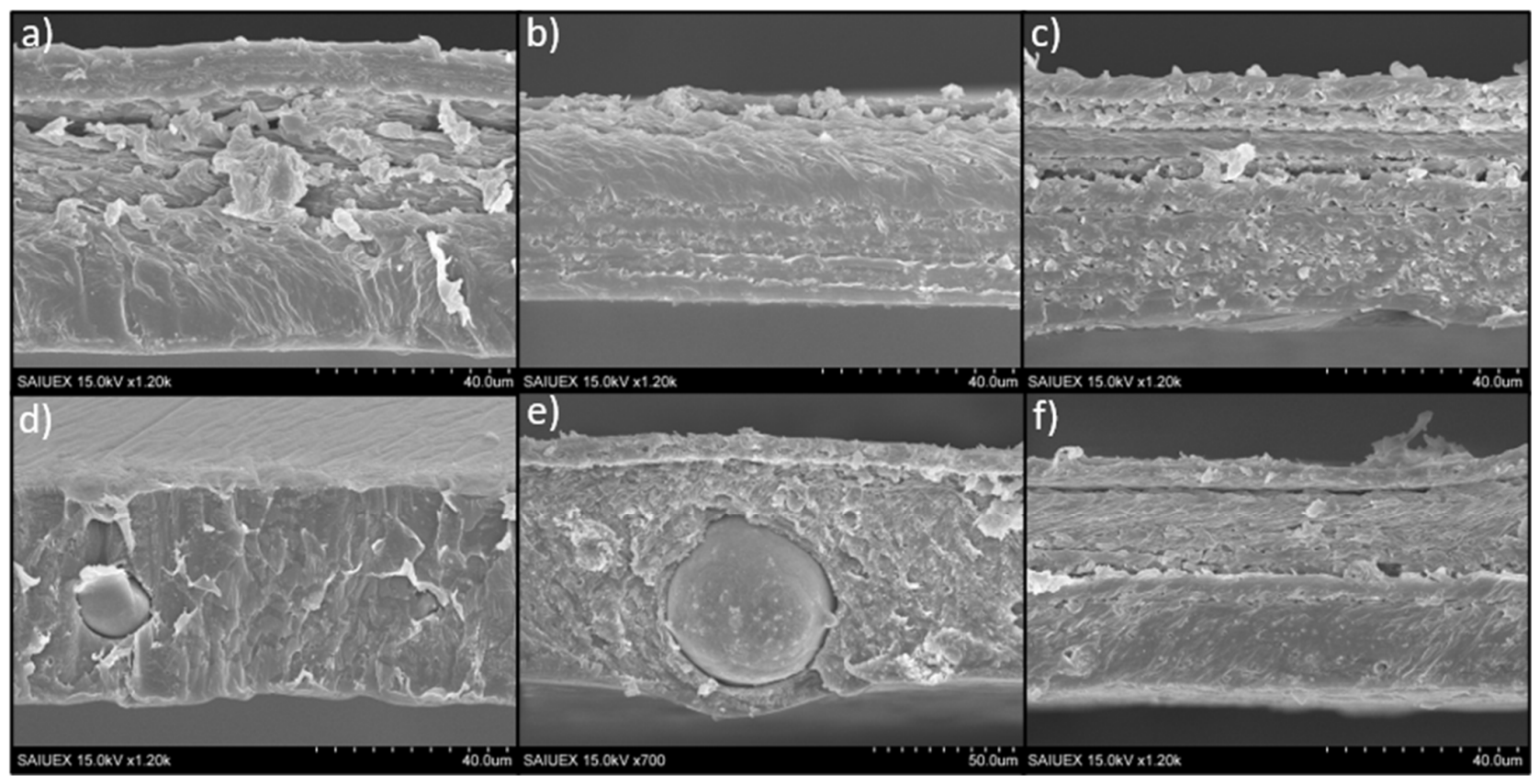

Figure 4. Cross-section images of S-PLA-0,0 (a), S-PLA-0,1 (b), S-PLA-0,10 (c), S-PLA-3,0 (d), S-PLA-3,1 (e) and S-PLA-3/10 (f) films.

Particularly, only in the case of S-PLA-3/0 films (Figure 4d), the laminar structure is not observed, probably because the magnesium particles favor a better packing of the polymer chains: the interaction between the $\mathrm{Mg}^{2+}$ and the oxygen atoms present in the 
PLA structure could be stronger than the steric hindrance caused by the methyl groups of the polymer chain. After adding surfactant, the laminar structure is again observed (Figure $4 \mathrm{e}, \mathrm{f})$, and comparing the cross-section images of the films containing $10 \%(w / w)$ of CTAB, it seems that, in the case of the Mg-containing films (S-PLA-3/10), the polymer matrix arrangement inside the sheets is slightly more compact than in the case without $\mathrm{Mg}$. This would be in agreement with the fact that the CTAB favors the mixing between the $\mathrm{Mg}$ particles and the PLA [10].

\section{Conclusions}

According to surface mass spectra, at $\mathrm{CTAB}$ concentrations above $5 \%(w / w)$, there is a noticeable presence of surfactant on the film surface. Moreover, the presence of CTAB in the polymer matrix with and without magnesium improves the wettability of the films, making them more suitable for cell adhesion. In addition, the higher the hydrophilicity, the higher the surfactant concentration, because there is a higher accumulation at the film-substrate interface, as demonstrated by ToF-SIMS surface mass spectra.

A layer-like distribution near the surface is revealed by the depth profiles. Although it depends on the surfactant concentration and the presence of $\mathrm{Mg}$, a CTAB + PLA mixed layer and a surfactant exclusion zone can always be observed.

Supplementary Materials: The following are available online: Figure S1. Relative intensities of $\mathrm{Br}^{-}$ and $\mathrm{C}_{4} \mathrm{H}_{7} \mathrm{O}_{2}{ }^{-}$ions as a function of sample type for PLA films containing CTAB and $\mathrm{Mg}$ casted on silicone and glass (side exposed to air); Figure S2. Depth profiles of G-PLA-0/0 (a), G-PLA-0/1 (b), G-PLA-0/10 (c), G-PLA-3/0 (d), G-PLA-3/1 (e) and G-PLA-3/10 (f) films; Figure S3. Depth profiles of S-PLA-0/0 (a), S-PLA-0/1 (b), S-PLA-0/10 (c), S-PLA-3/0 (d), S-PLA-3/1 (e) and S-PLA-3/10 (f) films (side exposed to air); Figure S4. Depth profiles of G-PLA-0/0 (a), G-PLA-0/1 (b), G-PLA0/10 (c), G-PLA-3/0 (d), G-PLA-3/1 (e) and G-PLA-3/10 (f) films (side exposed to air); Figure S5. Cross-section images of G-PLA-0,1 (a), G-PLA-0,10 (b), G-PLA-3,1 (c) and G-PLA-3/10 (d) films.

Author Contributions: Conceptualization, M.H.-O., V.L.-A., M.L.G.-M. and A.M.G.-M.; formal analysis, M.H.-O., V.L.-A., M.L.G.-M. and A.M.G.-M.; funding acquisition, M.L.G.-M. and A.M.G.-M.; investigation, M.H.-O. and V.L.-A.; methodology, M.L.G.-M. and A.M.G.-M.; supervision, M.L.G.M. and A.M.G.-M.; writing-original draft, M.H.-O., V.L.-A. and M.L.G.-M.; writing-review and editing, M.L.G.-M. and A.M.G.-M. All authors have read and agreed to the published version of the manuscript.

Funding: This research was funded by Junta de Extremadura and FEDER (grant number GR18153), project RTI2018-096862-B-I00, supported by FEDER (Fondo Europeo de Desarrollo Regional “Una Manera de hacer Europa"), Ministerio de Ciencia e Innovación del Gobierno de España, Agencia Española de Investigación, respectively.

Institutional Review Board Statement: Not applicable.

Informed Consent Statement: Not applicable.

Data Availability Statement: Data is contained within the article or Supplementary Materials.

Acknowledgments: ToF-SIMS was performed by the ICTS "NANBIOSIS", more specifically by the Surface Characterization and Calorimetry Unit of the CIBER in Bioengineering, Biomaterials \& Nanomedicne (CIBER-BBN) and the SACSS-SAIUEx of the University of Extremadura (UEx).

Conflicts of Interest: The authors declare no conflict of interest.

Sample Availability: Sample of the compounds are not available from the authors.

\section{References}

1. Sharma, R.; Jafari, S.M.; Sharma, S. Antimicrobial bio-nanocomposites and their potential applications in food packaging. Food Control 2020, 112, 107086. [CrossRef]

2. Murariu, M.; Dubois, P. PLA composites: From production to properties. Adv. Drug Deliv. Rev. 2016, 107, 17-46. [CrossRef] [PubMed]

3. Rasal, R.M.; Janorkar, A.V.; Hirt, D.E. Poly(lactic acid) modifications. Prog. Polym. Sci. 2010, 35, 338-356. [CrossRef] 
4. Abou-Zeid, R.E.; Diab, M.A.; Mohamed, S.A.A.; Salama, A.; Aljohani, H.A.; Shoueir, K.R. Surfactant-assisted poly(lactic acid)/cellulose nanocrystal bionanocomposite for potential application in paper coating. J. Renew. Mater. 2018, 6, 394-401. [CrossRef]

5. Arrieta, M.P.; Fortunati, E.; Dominici, F.; Rayón, E.; López, J.; Kenny, J.M. PLA-PHB/cellulose based films: Mechanical, barrier and disintegration properties. Polym. Degrad. Stab. 2014, 107, 139-149. [CrossRef]

6. Silva, C.G.; Campini, P.A.L.; Rocha, D.B.; Rosa, D.S. The influence of treated eucalyptus microfibers on the properties of PLA biocomposites. Compos. Sci. Technol. 2019, 179, 54-62. [CrossRef]

7. Zhou, H.; Nabiyouni, M.; Lin, B.; Bhaduri, S.B. Fabrication of novel poly(lactic acid)/amorphous magnesium phosphate bionanocomposite fibers for tissue engineering applications via electrospinning. Mater. Sci. Eng. C 2013, 33, 2302-2310. [CrossRef]

8. Kim, H.W.; Lee, H.H.; Knowles, J.C. Knowles Electrospinning biomedical nanocomposite fibers of hydroxyapaite/poly(lactic acid) for bone regeneration. J. Biomed. Mater. Res. Part A 2006, 79, 643-649. [CrossRef]

9. Fernández-Montero, A.; Lieblich, M.; Benavente, R.; González-Carrasco, J.L.; Ferrari, B. New approach to improve polymer$\mathrm{Mg}$ interface in biodegradable PLA/Mg composites through particle surface modification. Surf. Coat. Technol. 2020, 383, 125285. [CrossRef]

10. Fernández-Montero, A.; Lieblich, M.; Benavente, R.; González-Carrasco, J.L.; Ferrari, B. Study of the matrix-filler interface in PLA/Mg composites manufactured by Material Extrusion using a colloidal feedstock. Addit. Manuf. 2020, 33, 101142. [CrossRef]

11. Luque-Agudo, V.; Fernández-Calderón, M.C.; Pacha-Olivenza, M.A.; Pérez-Giraldo, C.; Gallardo-Moreno, A.M.; González-Martín, M.L. The role of magnesium in biomaterials related infections. Colloids Surf. B Biointerfaces 2020, 191, 110996. [CrossRef] [PubMed]

12. Witte, F. The history of biodegradable magnesium implants: A review. Acta Biomater. 2010, 6, 1680-1692, reprinted in Acta Biomater. 2015, 23, S28-S40. [CrossRef] [PubMed]

13. Cifuentes, S.C.; Frutos, E.; González-Carrasco, J.L.; Muñoz, M.; Multigner, M.; Chao, J.; Benavente, R.; Lieblich, M. Novel PLLA/magnesium composite for orthopedic applications: A proof of concept. Mater. Lett. 2012, 74, 239-242. [CrossRef]

14. Lee, J.H.; Khang, G.; Lee, J.W.; Lee, H.B. Interaction of different types of cells on polymer surfaces with wettability gradient. J. Colloid Interface Sci. 1998, 205, 323-330. [CrossRef] [PubMed]

15. Arima, Y.; Iwata, H. Effect of wettability and surface functional groups on protein adsorption and cell adhesion using well-defined mixed self-assembled monolayers. Biomaterials 2007, 28, 3074-3082. [CrossRef]

16. Zhang, J.; Severtson, S.J. Characterizing the distribution of sodium alkyl sulfate surfactant homologues in water-based, acrylic pressure-sensitive adhesive films. J. Phys. Chem. B 2011, 115, 8138-8144. [CrossRef]

17. Kiss, É.; Bertóti, I.; Vargha-Butler, E.I. XPS and wettability characterization of modified poly(lactic acid) and poly(lactic/glycolic acid) films. J. Colloid Interface Sci. 2002, 245, 91-98. [CrossRef]

18. Kiss, É.; Takács, M.G.; Bertóti, I.; Vargha-Butler, E.I. Surface properties of poly(lactic/glycolic acid)—Pluronic ${ }^{\circledR}$ blend films. Polym. Adv. Technol. 2003, 14, 839-846. [CrossRef]

19. Fukuoka, T.; Morita, T.; Saika, A.; Habe, H. Application of glycolipid biosurfactants as surface modifiers in bioplastics. J. Oleo Sci. 2018, 67, 1609-1616. [CrossRef]

20. Gîfu, I.C.; Maxim, M.E.; Cinteza, L.O.; Popa, M.; Aricov, L.; Leonties, A.R.; Anastasescu, M.; Anghel, D.F.; Ianchis, R.; Ninciuleanu, C.M.; et al. Antimicrobial activities of hydrophobically modified poly(acrylate) films and their complexes with different chain length cationic surfactants. Coatings 2019, 9, 244. [CrossRef]

21. Gyulai, G.; Pénzes, C.B.; Mohai, M.; Lohner, T.; Petrik, P.; Kurunczi, S.; Kiss, T.E. Interfacial properties of hydrophilized poly(lactic-co-glycolic acid) layers with various thicknesses. J. Colloid Interface Sci. 2011, 362, 600-606. [CrossRef] [PubMed]

22. Gromer, A.; Thalmann, F.; Hébraud, P.; Holl, Y. Simulation of vertical surfactant distributions in drying latex films. Langmuir 2017, 33, 561-572. [CrossRef] [PubMed]

23. Tezel, U.; Pavlostathis, S.G. Quaternary ammonium disinfectants: Microbial adaptation, Degradation and ecology. Curr. Opin. Biotechnol. 2015, 33, 296-304. [CrossRef]

24. Nakata, K.; Tsuchido, T.; Matsumura, Y. Antimicrobial cationic surfactant, cetyltrimethylammonium bromide, induces superoxide stress in Escherichia coli cells. J. Appl. Microbiol. 2011, 110, 568-579. [CrossRef]

25. Chen, P.; Lang, J.; Donadt, T.; Yu, Z.; Yang, R. Reduced Biofilm Formation at the Air-Liquid-Solid Interface via Introduction of Surfactants. ACS Biomater. Sci. Eng. 2021. [CrossRef]

26. Luque-Agudo, V.; Romero-Guzmán, D.; Fernández-Grajera, M.; González-Martín, M.L.; Gallardo-Moreno, A.M. Aging of Solvent-Casting PLA-Mg Hydrophobic Films: Impact on Bacterial Adhesion and Viability. Coatings 2019, 9, 814. [CrossRef]

27. Nassar, M.; Gromer, A.; Favier, D.; Thalmann, F.; Hébraud, P.; Holl, Y. Horizontal drying fronts in films of colloidal dispersions: Influence of hydrostatic pressure and collective diffusion. Soft Matter 2017, 13, 9162-9173. [CrossRef]

28. Li, J.; Li, Z.; Ye, L.; Zhao, X.; Coates, P.; Caton-Rose, F. Structure and biocompatibility improvement mechanism of highly oriented poly(lactic acid) produced by solid die drawing. Eur. Polym. J. 2017, 97, 68-76. [CrossRef]

29. Routh, A.F.; Russel, W.B. Horizontal drying fronts during solvent evaporation from latex films. AIChE J. 1998, 44, 2088-2098. [CrossRef]

30. Yiantsios, S.G.; Higgins, B.G. Marangoni flows during drying of colloidal films. Phys. Fluids 2006, 18, 082103. [CrossRef]

31. Mallégol, J.; Gorce, J.P.; Dupont, O.; Jeynes, C.; McDonald, P.J.; Keddie, J.L. Origins and effects of a surfactant excess near the surface of waterborne acrylic pressure-sensitive adhesives. Langmuir 2002, 18, 4478-4487. [CrossRef] 
32. Butt, H.J.; Kuropka, R.; Christensen, B. Latex film formation studied with the atomic force microscope: Influence of aging and annealing. Colloid Polym. Sci. 1994, 272, 1218-1223. [CrossRef]

33. Du Chesne, A.; Gerharz, B.; Lieser, G. The segregation of surfactant upon film formation of latex dispersions: An investigation by energy filtering transmission electron microscopy. Polym. Int. 1997, 43, 187-196. [CrossRef] 